Pacific Journal of Mathematics

PRODUCTS OF BANACH SPACES THAT ARE UNIFORMLY 


\title{
PRODUCTS OF BANACH SPACES THAT ARE UNIFORMLY ROTUND IN EVERY DIRECTION
}

\author{
MARK A. SMITH
}

\begin{abstract}
It is shown that the product of a collection of Banach spaces that are uniformly rotund in every direction (URED) over a URED Banach space need not be URED; this answers a question raised by $M$. M. Day. A positive result under an additional hypothesis is also proved.
\end{abstract}

Introduction. A Banach space $\dot{B}$ is uniformly rotund in every direction (URED) if and only if, for every nonzero member $z$ of $B$ and $\varepsilon>0$, there exists a $\delta>0$ such that $\|(1 / 2)(x+y)\| \leqq 1-\delta$ whenever $\|x\|=\|y\|=1, x-y=\alpha z$ and

$$
\|x-y\| \geqq \varepsilon \text {. }
$$

This generalization of uniform rotundity was introduced by Garkavi [3] to characterize Banach spaces in which every bounded subset has at most one Čebyšev center. Zizler [6] and Day, James, and Swaminathan [2] have investigated this geometrical notion more fully. The purpose of this note is to answer negatively the following question raised by M. M. Day [1, p. 148]: Is the product of a collection of URED Banach spaces over a URED Banach space still URED? In $\S 1$, a positive result is proved under an additional hypothesis; the counterexample, $\S 2$, is present exactly when this hypothesis fails.

Let $S$ be an index set. A full function space $X$ on $S$ is a Banach space of real valued functions $f$ on $S$ such that for each $f$ in $X$, each function $g$ for which $|g(s)| \leqq|f(s)|$ for each $s$ in $S$ is again in $X$ and $\|g\| \leqq\|f\|$.

Note that $X$ has a natural Banach lattice structure with positive cone $\{f \in X: f(s) \geqq 0$ for all $s \in S\}$ and that $X$ is order complete by its fullness. It follows easily from theorems of Lotz [4, p. 121] and McArthur [5, p. 5] that the following are equivalent:

(1) $X$ contains no closed sublattice order isomorphic to $\ell^{\infty}$.

(2) Each order interval in $X$ is compact.

If for each $s$ in $S$, a Banach space $B_{s}$ is given, let $P_{X} B_{s}$, the product of the $B_{s}$ over $X$, be the space of all those functions $x$ on $S$ such that (i) $x(s)$ is in $B_{s}$ for each $s$ in $S$, and (ii) if $f$ is defined by $f(s)=\|x(s)\|$ for all $s$ in $S$, then $f$ is in $X$. For each $x$ in $P_{X} B_{s}$, define $\|x\|=\|f\|_{X}$. With the above definitions, $\left(P_{X} B_{s} ;\|\cdot\|\right)$ is a Banach space. 
1. A positive result. The question of whether the product of a collection of URED spaces is isomorphic to a URED space was considered in [2, p. 1056]. There, it was shown that $P_{X} B_{8}$ is isomorphic to a URED space if each $B_{s}$ is URED, and if either (i) $S$ is countable or (ii) $X=\ell_{p}(S)$ for $1 \leqq p<\infty$. Here, the isometric question raised by Day is considered.

THEOREM. The product space $P_{X} B_{s}$ is uniformly rotund in the direction $z$ if each $B_{s}$ and $X$ is URED and the order interval $[0,\{\|z(s)\|\}]$ is compact.

Proof. Let $z$ be a nonzero member of $P_{X} B_{s}$ for which the order interval $[0,\{\|z(s)\|\}]$ is compact. Let $\left\{x_{n}\right\}$ and $\left\{y_{n}\right\}$ be sequences in $P_{X} B_{s}$ such that $\left\|x_{n}\right\|=\left\|y_{n}\right\|=1,\left\|x_{n}+y_{n}\right\| \rightarrow 2$ and $x_{n}-y_{n}=\alpha_{n} z$. Then

$$
\left\|x_{n}-\eta \alpha_{n} z\right\| \longrightarrow 1 \text { if } 0 \leqq \eta \leqq 1 .
$$

Define sequences $\left\{f_{n}\right\}$ and $\left\{g_{n}^{\theta}\right\}$, for $\theta=(1 / 2), 1$, by letting

$$
f_{n}(s)=\left\|x_{n}(s)\right\| \text { and } g_{n}^{\theta}(s)=\left\|x_{n}(s)-\theta \alpha_{n} z(s)\right\|
$$

for $s$ in $S$. Then $\left\|f_{n}\right\|=1$ and $\left\|g_{n}^{\theta}\right\| \rightarrow 1$. Since $\left\|2 x_{n}(s)-\theta \alpha_{n} z(s)\right\| \leqq$ $f_{n}(s)+g_{n}^{\theta}(s)$ for each $s$ and $\left\|2 x_{n}-\theta \alpha_{n} z\right\| \rightarrow 2$, we have

$$
\left\|f_{n}+g_{n}^{\theta}\right\| \longrightarrow 2 \text {. }
$$

For each $n$ and $s$, note that $\left|f_{n}(s)-g_{n}^{\theta}(s)\right| \leqq\left\|\theta \alpha_{n} z(s)\right\|$. By the compactness hypothesis, there exist $h^{\theta}$ in $X$ and a sequence $\left\{n_{k}\right\}$ such that

$$
f_{n_{k}}-g_{n_{k}} \longrightarrow h^{\theta} \text {. }
$$

Since $X$ is URED, it follows by Theorem 1 of [2] that $h^{\theta}=0$. Thus $\left\|x_{n}(s)\right\|-\left\|x_{n}(s)-\theta \alpha_{n} z(s)\right\| \rightarrow 0$ for each $s$ in $S$ and $\theta=(1 / 2), 1$. Choosing $s$ such that $z(s) \neq 0$ and using the fact that $B_{s}$ is URED, we conclude that $\alpha_{n} \rightarrow 0$. This completes the proof.

The following result is an immediate consequence of the theorem and the above remarks concerning full function spaces.

COROLLARY. The product space $P_{X} B_{s}$ is URED if each $B_{s}$ and $X$ is URED and $X$ contains no closed sublattice order isomorphic to $\iota^{\infty}$.

2. The counterexample. An equivalent full function space norm \|\|$\cdot \mid \|$ on $\ell^{\infty}$ that is URED and a sequence $\left\{B_{i}\right\}$ of URED 
Banach spaces are defined such that, for $X=\left(\ell^{\infty} ;|| \cdot|\||\right)$, the product space $P_{X} B_{i}$ is not URED.

Let $\left\{a_{j}\right\}_{j=2}^{\infty}$ be a sequence of positive real numbers such that $\sum_{2}^{\infty} a_{j}^{2}=1$. For $x=\left(x_{j}\right)_{j=1}^{\infty}$ an element of $\iota^{\infty}$, define

$$
\||| x \mid\|=\left[\|x\|_{\infty}^{2}+\sum_{2}^{\infty} \alpha_{j}^{2}\left(\left|x_{1}\right|+\left|x_{j}\right|\right)^{2}\right]^{1 / 2} .
$$

It is straightforward to verify that $\|\cdot \cdot\| \mid$ is a norm on $\ell^{\infty}$ and that $\|\cdot\|_{\infty} \leqq\|\cdot \mid\| \leqq \sqrt{5}\|\cdot\|_{\infty}$. Also note that $\|x|\|=\|||x|\| \|$ and that $0 \leqq x \leqq y$ implies $\left\|x|\|\leqq\| y \||\right.$ for all $x$ and $y$ in $\ell^{\infty}$. Therefore $\||\cdot|\|$ is an equivalent full function space norm on $\ell^{\infty}$.

To show $\left(\ell^{\infty} ;\|\cdot \mid\|\right)$ is URED, let $z$ be a member of $\ell^{\infty}$ such that $\||z|\|=1$. If $\|x|\|=\||\| y \|=1$, where $y=x+\alpha z$, then $x+y=$ $2 x+\alpha z$ and

$$
\begin{aligned}
\| \mid 2 x & +\alpha z \mid\left\|^{2}=\right\| 2 x+\alpha z \|_{\infty}^{2}+\sum_{2}^{\infty} \alpha_{j}^{2}\left(\left|2 x_{1}+\alpha z_{1}\right|+\left|2 x_{j}+\alpha z_{j}\right|\right)^{2} \\
\leqq & \left(\|x\|_{\infty}+\|x+\alpha z\|_{\infty}\right)^{2}+\sum_{2}^{\infty} a_{j}^{2}\left(\left|x_{1}\right|+\left|x_{1}+\alpha z_{1}\right|+\left|x_{j}\right|+\left|x_{j}+\alpha z_{j}\right|\right)^{2} \\
= & 4-\left[\left(\|x\|_{\infty}-\|x+\alpha z\|_{\infty}\right)^{2}\right. \\
& \left.\quad+\sum_{2}^{\infty} a_{j}^{2}\left(\left|x_{1}+\alpha z_{1}\right|+\left|x_{j}+\alpha z_{j}\right|-\left|x_{1}\right|-\left|x_{j}\right|\right)^{2}\right]
\end{aligned}
$$

and hence

$$
\begin{aligned}
{[1+} & \left.\left.\left\|\left|x+\frac{1}{2} \alpha z\right|\right\|\right|^{2}\right]^{1 / 2} \geqq \frac{1}{2}\left[\left(\|x\|_{\infty}-\|x+\alpha z\|_{\infty}\right)^{2}\right. \\
& \left.+\sum_{2}^{\infty} a_{j}^{2}\left(\left|x_{1}+\alpha z_{1}\right|+\left|x_{j}+\alpha z_{j}\right|-\left|x_{1}\right|-\left|x_{j}\right|\right)^{2}\right]^{1 / 2} .
\end{aligned}
$$

Similarly, using $2\left(\left\||| x||^{2}+\right\||| x+(1 / 2) \alpha z \mid \|^{2}\right) \leqq 4$, we obtain

$$
\begin{aligned}
& {\left[1-\left.||\left|x+\frac{1}{4} \alpha z\right|\right|^{2}\right]^{1 / 2} \geqq \frac{1}{2}\left[\left(\|x\|_{\infty}-\left\|x+\frac{1}{2} \alpha z\right\|_{\infty}\right)^{2}\right.} \\
& \left.\quad+\sum_{2}^{\infty} \alpha_{j}^{2}\left(\left|x_{1}+\frac{1}{2} \alpha z_{1}\right|+\left|x_{j}+\frac{1}{2} \alpha z_{j}\right|-\left|x_{1}\right|-\left|x_{j}\right|\right)^{2}\right]^{1 / 2} .
\end{aligned}
$$

It is sufficient to show that for each $\varepsilon>0$ the sum of the right members of (1) and (2) is bounded from zero, uniformly for all $x$ such that ||$|x|\|=|\|x+\alpha z \mid\|=1$ with $| \alpha \mid>\varepsilon$.

(i) If $z_{1}=0$, choose any $k$ with $z_{k} \neq 0$. Then at least one of $\left|\left(\left|x_{k}+\alpha z_{k}\right|-\left|x_{k}\right|\right)\right|$ or $\left|\left(\left|x_{k}+(1 / 2) \alpha z_{k}\right|-\left|x_{k}\right|\right)\right|$ is as great as $2^{-2}\left|\alpha z_{k}\right|$, so either the right member of (1) or the right member of (2) is greater than $2^{-3} a_{k} \varepsilon\left|z_{k}\right|$.

(ii) If $z_{1} \neq 0$ and $\left|z_{k}\right|<2^{-3}\left|z_{1}\right|$ for some $k$, then either $\left|\left(\left|x_{1}+\alpha z_{1}\right|-\left|x_{1}\right|\right)\right|$ or $\left|\left(\left|x_{1}+(1 / 2) \alpha z_{1}\right|-\left|x_{1}\right|\right)\right|$ is as great as $2^{-2}\left|\alpha z_{1}\right|$, but 
$\left|\left(\left|x_{k}+\alpha z_{k}\right|-\left|x_{k}\right|\right)\right|<2^{-3}\left|\alpha z_{1}\right|$ and $\left|\left(\left|x_{k}+(1 / 2) \alpha z_{k}\right|-\left|x_{k}\right|\right)\right|<2^{-4}\left|\alpha z_{1}\right|$, so either the right member of (1) or the right member of (2) is greater than $2^{-4} a_{k} \varepsilon\left|z_{1}\right|$.

(iii) If $z_{1} \neq 0$ and $\left|z_{j}\right| \geqq 2^{-3}\left|z_{1}\right|$ for all $j$, then either

or

$$
\left.\begin{array}{c}
\left|\left(\|x\|_{\infty}-\|x+\alpha z\|_{\infty}\right)\right|>2^{-5} \varepsilon\left|z_{1}\right| \\
\left|\left(|| x\left\|_{\infty}-\right\| x+\frac{1}{2} \alpha z \|_{\infty}\right)\right|>2^{-5} \varepsilon\left|z_{1}\right|,
\end{array}\right\}
$$

and so either the right member of (1) or the right member of (2) is greater than $2^{-6} \varepsilon\left|z_{1}\right|$. To prove (3), we need only observe that if $\left|\left(\|x\|_{\infty}-\|x+(1 / 2) \alpha z\|_{\infty}\right)\right|<2^{-5}\left|\alpha z_{1}\right|$ and $j$ is chosen so that $\mid\left(\|x\|_{\infty}-\right.$ $\left.\left|x_{j}+(1 / 2) \alpha z_{j}\right|\right)\left|<2^{-5}\right| \alpha z_{1} \mid$, then $\left|x_{j}+(1 / 2) \alpha z_{j}\right|>\left|x_{j}\right|-2^{-2}\left|\alpha z_{j}\right|$ and hence $\left|x_{j}+\alpha z_{j}\right|=\left|x_{j}+(1 / 2) \alpha z_{j}\right|+(1 / 2)\left|\alpha z_{j}\right|$. Thus

$$
\|x+\alpha z\|_{\infty}>\|x\|_{\infty}-2^{-5}\left|\alpha z_{1}\right|+\frac{1}{2}\left|\alpha z_{j}\right|>\|x\|_{\infty}+2^{-5} \varepsilon\left|z_{1}\right| .
$$

This shows that $\|\cdot|\||$ is URED.

Now, let $X=\left(\ell^{\infty} ;\|\cdot|\||)\right.$ and for each positive integer $i$, let $B_{i}$ be the two dimensional $\ell^{i+1}$ space. Note that each $B_{i}$ is URED. Let $z$ in $P_{X} B_{i}$ be defined by $z(i)=(1,0)$ in $B_{i}$ for each $i$. For each $n \geqq 2$, let $x_{n}$ and $y_{n}$ in $P_{X} B_{i}$ be defined by

$$
x_{n}(i)=\left\{\begin{array}{lll}
(0,0) & \text { if } & i=1 \\
\left(\frac{1}{2}, b_{n}\right) & \text { if } & i=n \\
(1,0) & \text { if } & i \neq 1, n
\end{array}\right.
$$

and

$$
y_{n}(i)= \begin{cases}(-1,0) & \text { if } \quad i=1 \\ \left(-\frac{1}{2}, b_{n}\right) & \text { if } \quad i=n \\ (0,0) & \text { if } \quad i \neq 1, n\end{cases}
$$

where $b_{n}$ is chosen such that $b_{n}>0$ and $(1 / 2)^{n+1}+\left(b_{n}\right)^{n+1}=1$. Then $\left\|x_{n}\right\|=\sqrt{2},\left\|y_{n}\right\|=\left(2+3 a_{n}^{2}\right)^{1 / 2}$,

$$
\left\|x_{n}+y_{n}\right\|=\left[4 b_{n}^{2}+4+\left(4 b_{n}^{2}+4 b_{n}-3\right) a_{n}^{2}\right]^{1 / 2},
$$

and $x_{n}-y_{n}=z$ for each $n \geqq 2$. Since $b_{n} \rightarrow 1$ and $a_{n} \rightarrow 0$, it follows that $\left\|y_{n}\right\| \rightarrow \sqrt{2}$ and $\left\|x_{n}+y_{n}\right\| \rightarrow 2 \sqrt{2}$, and hence $P_{X} B_{i}$ is not URED.

The author thanks the referee for helpful suggestions. 


\section{REFERENCES}

1. M. M. Day, Normed linear spaces, Ergebnisse der Math., Springer-Verlag, New York, 1973.

2. M. M. Day, R. C. James, and S. Swaminathan, Normed linear spaces that are uniformly convex in every direction, Canad. J. Math., 23 (1971), 1051-1059.

3. A. L. Garkavi, The best possible net and best possible cross section of a set in a normed space, Izv. Akad. Nauk SSSR Ser. Mat., 26 (1962), 87-106; Amer. Math. Soc. Transl., Ser. 2, 39 (1964), 111-132.

4. H. P. Lotz, Minimal and reflexive Banach lattices, Math. Ann., 209 (1974), 117-126.

5. C. W. McArthur, Convergence of monotone nets in ordered topological vector spaces, Studia Math., 34 (1970), 1-16.

6. V. Zizler, On some rotundity and smoothness properties of Banach spaces, Dissertationes Math. (Rozprawy Mat.) No. 87 (1971).

Received April 7, 1976 and in revised form April 11, 1977. This paper is a revised version of part of the author's $\mathrm{Ph}$. D. thesis written at the University of Illinois under the supervision of Professor M. M. Day.

LAKE Forest COLLEGE

LAKE FOREST, IL 60045

AND

MiAMI UNIVERSITY

OXFORD, OH 45056 



\section{PACIFIC JOURNAL OF MATHEMATICS}

EDITORS

RICHARD ARENS (Managing Editor)

University of California

Los Angeles, California 90024

C. W. Curtis

University of Oregon

Eugene, OR 97403

C. C. MOORE

J. DUGUNDJI

Department of Mathematics University of Southern Californa Los Angeles, California 90007

R. Finn AND J. Milgram Stanford University Stanford, California 94305

University of California

Berkeley, CA 94720

\section{ASSOCIATE EDITORS}

E. F. BeCKENBACH

B. H. NeUMANN

F. WOLF

K. YosHida

\section{SUPPORTING INSTITUTIONS}

UNIVERSITY OF BRITISH COLUMBIA UNIVERSITY OF SOUTHERN CALIFORNIA CALIFORNIA INSTITUTE OF TECHNOLOGY UNIVERSITY OF CALIFORNIA MONTANA STATE UNIVERSITY UNIVERSITY OF NEVADA, RENO STANFORD UNIVERSITY UNIVERSITY OF TOKYO UNIVERSITY OF UTAH NEW MEXICO STATE UNIVERSITY WASHINGTON STATE UNIVERSITY OREGON STATE UNIVERSITY UNIVERSITY OF WASHINGTON UNIVERSITY OF OREGON OSAKA UNIVERSITY 


\section{Pacific Journal of Mathematics \\ Vol. 73, No. 1 \\ March, 1977}

Thomas Robert Berger, Hall-Higman type theorems. $V \ldots \ldots \ldots \ldots \ldots \ldots \ldots$

Frank Peter Anthony Cass and Billy E. Rhoades, Mercerian theorems via

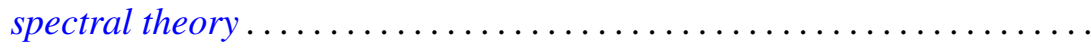

Morris Leroy Eaton and Michael David Perlman, Generating $\mathrm{O}(n)$ with

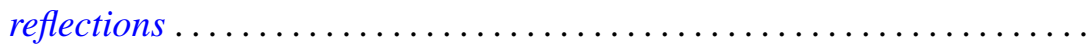

Frank John Forelli, Jr., A necessary condition on the extreme points of a

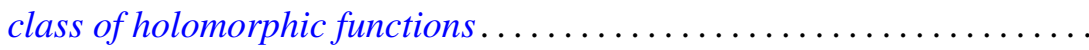

Melvin F. Janowitz, Complemented congruences on complemented

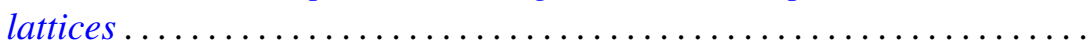

Maria M. Klawe, Semidirect product of semigroups in relation to amenability, cancellation properties, and strong $F \phi$ lner conditions....

Theodore Willis Laetsch, Normal cones, barrier cones, and the "spherical image" of convex surfaces in locally convex spaces ................

Chao-Chu Liang, Involutions fixing codimension two knots.............

Joyce Longman, On generalizations of alternative algebras .............

Giancarlo Mauceri, Square integrable representations and the Fourier

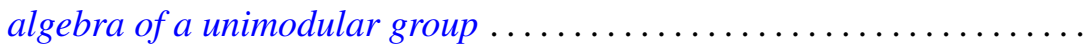

J. Marshall Osborn, Lie algebras with descending chain condition...

John Robert Quine, Jr., Tangent winding numbers and branched

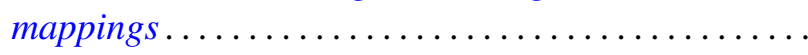

Louis Jackson Ratliff, Jr. and David Eugene Rush, Notes on ideal covers and associated primes .

H. B. Reiter and N. Stavrakas, On the compactness of the hyperspace of faces.

Walter Roth, A general Rudin-Carlson theorem in Banach-spaces ..

Mark Andrew Smith, Products of Banach spaces that are uniformly rotund in every direction.

Roger R. Smith, The R-Borel structure on a Choquet simplex ...

Gerald Stoller, The convergence-preserving rearrangements of real infinite series. ...

Graham H. Toomer, Generalized homotopy excision theorems modulo a Serre class of nilpotent groups...

Norris Freeman Weaver, Dehn's construction and the Poincaré conjecture....

Steven Howard Weintraub, Topological realization of equivariant intersection forms... 